Fanum

Sociológico
Forum Sociológico

Série II

$18 \mid 2008$

Explorando os interstícios urbanos

\title{
(Com)fusão na cidade: Tag, Ácido e Diamante
}

\section{Luciano Spinelli}

\section{OpenEdition}

Journals

Edição electrónica

URL: https://journals.openedition.org/sociologico/256

DOI: 10.4000/sociologico.256

ISSN: 2182-7427

\section{Editora}

CICS.NOVA - Centro Interdisciplinar de Ciências Sociais da Universidade Nova de Lisboa

Edição impressa

Data de publição: 1 junho 2008

Paginação: 49-57

ISSN: 0872-8380

\section{Refêrencia eletrónica}

Luciano Spinelli, «(Com)fusão na cidade: Tag, Ácido e Diamante », Forum Sociológico [Online], 18| 2008, posto online no dia 20 julho 2012, consultado o 31 março 2022. URL: http://journals.openedition.org/ sociologico/256 ; DOI: https://doi.org/10.4000/sociologico.256

Este documento foi criado de forma automática no dia 31 março 2022.

(C) CICS.NOVA 


\title{
(Com)fusão na cidade: Tag, Ácido e Diamante
}

\author{
Luciano Spinelli
}

“Em plena confusão urbana, a fotografia recria o equivalente do deserto, um isolamento fenomenal." Jean Baudrillard

Figuras 1, 2 e 3: GOBE, métro Strasbourg Saint Denis.
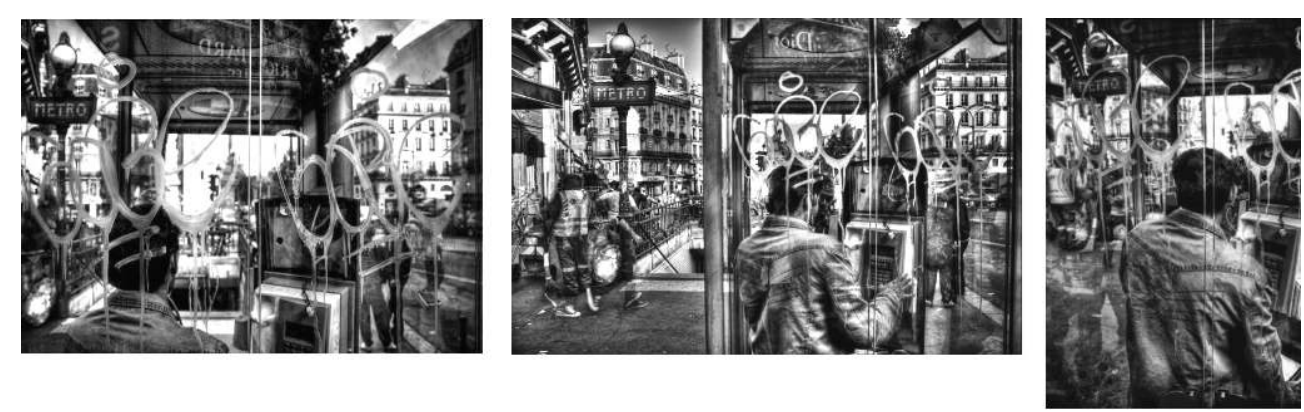

1 A cidade tornou-se o habitat natural do homem e o mobiliário urbano convenceu-nos de que ela é a nossa casa. Quando estamos fora do lar, abrigamo-nos junto a esses móveis de aparência durável e estilo padronizado sempre que um pouco de conforto se faz necessário. Esperando um ônibus, bebendo a água de uma fonte, usando um banheiro público ou telefonando de uma cabine, estamos em relação com os móveis da cidade.

2 Vamos observar um deles, as cabines telefônicas da cidade de Paris. Falar da revolução nas telecomunicações causada pelo telefone móvel e posteriormente pela internet sem fio, é lugar-comum há algum tempo. Vamos deixar o telefone em segundo plano e fixar nosso olhar nessas cabines para entrever questões sociais e reflexos citadinos. Perguntamo-nos quem, na cidade de Paris, utiliza essas cabines e com que objetivos?

o perfil social dessas pessoas interessa-nos, pois o número de usuários dos telefones públicos está em longo declínio, e a cabine telefônica tem-se tornado um mobiliário urbano agonizante. Em conseqüência desse desinteresse, as cabines passam a ser um 
dos poucos territórios de sombra a subsistir na cidade de Paris, mesmo que em plena luz do dia. Entender os seus usos e principalmente observar que inscrições elas transportam são questões fundamentais no nosso objetivo de ler a cidade olhando através do jogo de espelhos que as cabines nos proporcionam.

Vamos deter-nos nesses compartimentos de forma a entender uma leitura da cidade de Paris, permeada por signos por vezes despercebidos ao olhar fugaz do transeunte. Para isso vamos empregar a fotografia de forma a eternizar um ponto de vista momentâneo e a agregar a esse texto o móvel urbano que acabamos de descrever. Primeiramente, vamos ver onde essas cabines se localizam, sob qual prisma metodológico as abarcamos e com que técnica intuímos a restituição fotográfica. Vamos então entender o vínculo social latente nessas paredes envidraçadas, a leitura da sinalética urbana refletida, e a importância dos detalhes "fora de campo" na constituição de um imaginário parisiense.

\section{A cidade de Paris}

5 Nasce na França, em 1955, a empresa JCDecaux, que porta as iniciais do seu fundador Jean-Claude Decaux. Com o passar do tempo, Paris tornou-se o laboratório dessa empresa do ramo midiático publicitário, que mobiliou os seus espaços públicos com objetos ambíguos, de um lado servindo as pessoas, de outro, anunciando produtos. É o caso do clássico "Abribus Standard" criado em 1970. Essa paragem de autocarro, além de proteger as pessoas do mau tempo, oferece onde se sentar e dá visibilidade a um anúncio publicitário. É nessa ambivalência, entre o conforto do habitante e a venda de um suporte midiático, que vamos observar um dos mobiliários urbanos esquecidos da cidade de Paris: as cabines de telefone público.

6 Essas cabines, de forma quadrangular, são inteiramente envidraçadas e dotadas de uma porta de vidro. 0 chão e o teto da cabine são metálicos e o telefone fica preso a uma viga central também metálica, que interliga duas a três cabines. Esses complexos de cabines telefônicas interessam-nos pelas suas longas linhas verticais interligadas a um solo quadrangular. Quando lançamos o nosso olhar a esse mobiliário citadino, vemos através das suas várias lâminas de vidros entrepostas uma cidade distorcida. Comparável a um diamante que reflete ângulos do urbano, essa cabine compõe certamente um prisma que nos permite entrever uma outra cidade, com os seus outros habitantes.

7 Em Paris, construir e demolir são tarefas praticamente impossíveis. Com o seu perímetro circular restrito, a sua linha do horizonte com imóveis haussmannianos que raramente excedem os seis andares e o seu subsolo fragilizado por um desgaste histórico que vai das catacumbas ao metrô, a cidade parece fixada no tempo. Se comparada à metamorfose dos ares citadinos que sopram no Oriente, como em Xangai, Pequim ou Dubai, na capital francesa paira um marasmo arquitetônico. Porém, essas camadas históricas que a envolvem fazem dela um organismo complexo, no qual a população tem o seu imaginário impregnado pelo local. Um exemplo desse apego territorial é dado por Marc Augé no estudo que fez sobre o metropolitano parisiense (Augé, 2001), ao notar que, quando passava pelas estações subterrâneas, imaginava com precisão a cidade que se erguia sobre a sua cabeça.

8 Nessa cidade orgânica, em referência à noção de "ecologia urbana" delineada pela Escola de Chicago, percebemos que a experiência social se assemelha a um ecossistema no qual a cidade se tornou o habitat natural do homem. Essa criação humana é 
explicitada por Robert Park nos seguintes termos: "indiretamente e sem ter clara consciência da natureza da sua obra, criando a cidade, o homem recriou-se a si mesmo. É nesse sentido que podemos considerar a cidade como um laboratório social" (Robert Park in Grafmeyer, Y. e Joseph, I.; 1984, 163).

9 Esse laboratório onde o homem testa as suas hipóteses do bem viver em sociedade é uma construção mutante: viva e em movimento. No ectoderme desse ser coletivo repousa o mobiliário e o imobiliário urbano, fincado ao chão por vigas de concreto que transpassam um mesoderme, no qual circulam água, esgoto, metrô, até chegar no mais profundo endoderme, onde se encontram alguns poucos abrigos antinucleares.

10 As interpretações da cidade enquanto corpo não se detém unicamente no nível da pele. As publicações do Grupo de Trabalho de Vancouver (Timmer e Seymoar, 2006), realizadas durante o Fórum Urbano Mundial de 2006, apontam para uma "cidade habitável" dotada de: um cérebro representado pelo governo e pela participação social; um coração simbolizado pelos valores comuns e as noções de identidade e pertencimento; órgãos que são o centro da cidade; as zonas industriais e comerciais e, finalmente, de um sistema circulatório caracterizado pelos transportes coletivos.

11 É nesse ser complexo, ou melhor, nesse meio ambiente parisiense que as cabines telefônicas aqui em questão fazem corpo com a cidade. Como é da praxe dizer, elas são móveis partilhados num espaço público. Vamos olhar essas cabines para ver nelas a cidade na qual estão fixadas.

\section{O passeio do olhar}

12 O ponto de vista que lançamos à cidade é fruto de um exercício etnográfico realizado junto a grafiteiros na Europa e no Brasil, do qual resultam alguns artigos ${ }^{2}$. A metodologia de pesquisa empregue foi inspirada no interaccionismo simbólico ${ }^{3}$. Através dela, desenvolvemos uma pesquisa de campo que lançou um ponto de vista sobre a comunicação urbana e as relações tribais expressas entre os autores das assinaturas vistas nos suportes citadinos.

As referências que contribuíram para a observação individual do urbano foram antes desenvolvidas em grupo. Ou melhor, em grupos, pois uma perspectiva emic foi dada pelo trabalho de campo junto de grafitters, e uma perspectiva etic foi tecida junto ao grupo de estudos CeaQ (Centre d'Études sur l'Actuel et le Quotidien) da Universidade de Paris V Descartes - Sorbonne. Em 2007, realizamos com este grupo um ciclo de "Ballades Urbaines". Nessas ocasiões, reunimos os integrantes de forma interdisciplinar ao redor da antropologia, sociologia, arquitetura e fotografia, para flanarmos e capturarmos uma realidade de outra Paris. Equipados de câmeras de vídeo e fotografia, derivamos por locais como a Petite Ceinture de Paris, o 18..$^{\circ}$ bairro e seus graffitis alados, as novas obras arquitetônicas do $13 .^{\circ}$ bairro.

14 Foi inspirado nesse método de trabalho, enraizado numa inter-subjetividade, que me guiei na realização da narrativa fotográfica aqui apresentada, e é por isso que utilizo a primeira pessoa do plural para expor minha experiência. Não por mera convenção acadêmica, mas sobretudo pelo fato de que o olhar lançado sobre a cidade foi previamente inferido coletivamente. Esse olhar fotográfico guia o artigo que, por sua estrutura e referências, se assemelha a um ensaio em etno-sociologia visual. A fotografia é então primordial: na constituição do objeto de análise propriamente dito; 
como constituinte de um vínculo social; e, principalmente, como forma narrativa. A ela e à sua importância metodológica será dedicado o próximo tópico, mas primeiramente vamos identificar onde e como pousa o nosso olhar.

O olhar etnográfico é chave na concepção desse escrito. A partir da relação com o pesquisado o olhar do pesquisador foi gradualmente educado no objetivo de interpretar o real a partir da visão do grafiteiro. A partir de uma experiência coletiva pretendemos inferir um ponto de vista individual que abarque facetas da cidade pós-moderna. Baseamo-nos na noção de mediance, tecida por Augustin Berque (Berque, 1990), através da qual a técnica prolonga a corporalidade para fora do corpo. Pela fotografia interpretamos a cidade através de um olhar intuitivo, habituado a entrever e desvendar os graffitis que marcam a pele da nossa casa.

Tratando-se de graffiti, um universo alargado de possibilidades estilísticas torna-se possível. Entretanto, é importante precisar que consideramos as pessoas que fazem os $\operatorname{tags}^{4}$, ácido fluorídrico vistos nas cabines telefônicas, como inseridos no universo do graffiti parisiense, que é em parte influenciado pela escola hip-hop norte-americana. A ênfase está na escrita constante e repetida do pseudônimo, feita por toda a cidade, com técnicas que vão do tag ao master piece no intuito de getting up ${ }^{5}$ (do inglês "levantar-se", "erguer-se", que na gíria do graffiti americano significa dar visibilidade ao pseudônimo).

As motivações que levam o jovem a marcar o seu nome tribal pela cidade são das mais diversas, entre as quais a de obter reconhecimento, respeito e fama ${ }^{6}$. Em busca de visibilidade, os grafiteiros conquistam simbolicamente a cidade. Essa ordem de reciprocidade pode ser entendida no exemplo seguinte: o graffiti gigante feito pelo $\mathrm{Crew}^{7}$ MTA - Metro Transit Assassins - de Los Angeles, medindo 15 metros de altura e com a extensão de dois campos de futebol, confirmou a fama dos integrantes do grupo! Alguns deles eram também conhecidos no meio do street art e vendiam telas grafitadas. Por serem grafiteiros que contavam diversos feitos ilegais, eles eram respeitados e conhecidos, pessoas públicas consideradas artistas e por isso facilmente inculpados pela polícia, por causa do graffiti gigante e ilegal que fizeram.

18 A dualidade por vezes antagônica entre um graffiti legal e artístico e um graffiti ilegal tido por vandalismo, considerado um "crime de estilo", é tecida por Jeff Ferrell (1993). Por outro lado, autores latino-americanos (Cruz, 2004; Lara, 1996) apontam para a importância de um graffiti tornado arte de rua, forma de expressão e inclusão social.

Legal ou ilegal, o graffiti é da rua, feito nos espaços de visibilidade da cidade como os explicitados no estudo de caso que Ricardo Campos (2009) realizou no Bairro Alto de Lisboa. Vemos que o processo de higienização aplicado a esse bairro engendra a subseqüente recriminação da atividade dos grafiteiros portugueses que entoavam um diálogo entre a arte e o vandalismo. Tratando-se de França, país no qual realizamos o estudo etnográfico, a recriminação do graffiti é regra, e o tag com ácido é tido como delito grave. A obra In Situ, de Stéphanie Lemoine e Julien Terral (2005), traça um panorama histórico da intervenção visual urbana nesse país. Ela explicita a passagem da expressão contestatória pelos muros da cidade a um graffiti hip-hop inseparável das suas motivações sociais e estilísticas.

Devido à complexidade do tema graffiti, vamo-nos dedicar ao exercício reflexivo de derivar a palavra que vemos grafitada no objeto cabine telefônica como analogia que serve à compreensão do ecossistema parisiense, com suas interações sociais e visuais. 0 método de trabalho mostrou-se então mais solitário, quando comparado com as aventuras etnográficas noturnas levadas durante o trabalho de campo junto a alguns 
crews de writers. Porém, tirar fotos de uma cidade não se parece em nada com a fotografia em estúdio ou de naturezas mortas. Estamos face a ritmos do habitante no seu habitat, com seus humores e suas fricções: as fotos resultantes deixam isso claro.

21 Esse artigo é ensaísta, fruto da deambulação de um autor fotógrafo, numa rua que, segundo Walter Benjamin, "conduz o flâneur a um tempo desaparecido. Para ele, todas são íngremes. Conduzem para baixo" (Benjamim, 1994: 190). Em contraponto à admiração que Walter Benjamin dedica às vitrines das "passagens parisienses" (Benjamim, 1986) do século XIX, nós dedicamo-nos a observar outras vitrines. Diferimos sobre o conteúdo, mas certamente não sobre a forma de contemplar essas paredes transparentes. Nas nossas vitrines pouco está à venda, mas uma outra cidade se oferece ao olhar, tal como nas antigas galerias que ainda persistem nos meandros das ruelas parisienses.

Esses resquícios típicos de um cenário francês estão saindo de moda frente ao brilho das vitrines dos shopping centers e de outros "não-lugares" (Augé, 1992), que dão a Paris o ar metropolitano de uma cidade global. De fato, os não-lugares, devidamente descritos por Marc Augé na obra homônima, são proporcionalmente opostos ao que entrevemos. "Assim como os lugares antropológicos que criam um social orgânico, os não-lugares criam uma contratualidade solitária. Como imaginar a análise Durkheimiana de uma sala de espera de Roissy?" (Augé, 1992: 119), questiona o autor em alusão ao segundo maior aeroporto de Paris.

É esse "social orgânico" que tentamos observar, com seus resquícios únicos de uma cidade em movimento. Os detalhes que logo mais serão descritos fazem das cabines telefônicas parisienses um mobiliário urbano sem precedentes, proporcional às vermelhas e tradicionais cabines telefônicas inglesas. Essa cabine transparente é um lugar social, um lugar de socialização, se considerada a relação entre quem telefona e quem se encontra do outro lado da linha.

Essa função social da cabine, também vista nas fotografias, vai da oferta de um telefone para a comunicação entre duas pessoas a um suporte físico para a escrita urbana, que comunica com os habitantes. Nelas percebemos as sombras e os rastros das pessoas que ali passaram, os rostos que se sobrepõem, os reflexos dos prédios, a marca de um tag. Elementos de uma socialização fria entre indivíduos que se cruzam sem se tocarem.

o tempo também é único, assim como a luz que trespassa, reflete e é refratada pelo vidro. As fotos dão mostras de um imaginário poético inferido sobre quem telefona. Essa abordagem inspira-se na fenomenologia, por estudar as imagens urbanas como uma estética cognitiva, a partir da práxis e da sua sedimentação de sentido. Levamos em conta a repercussão dessas representações citadinas no sujeito-leitor; leitor que é não somente quem observa as fotografias ou lê esse artigo, e, sim, o habitante de Paris, que se depara cotidianamente com as cabines telefônicas e as observa sobre um determinado prisma.

Vamos deter a nossa atenção na restituição que elaboramos da cabine telefônica através da imagem fotográfica, uma criação capaz de abarcar iconograficamente o nosso objeto. A fotografia passa a ter uma função narrativa independente, em paralelo ao texto. Metodologicamente, ela assemelha-se a uma fotoetnografia que, segundo Eduardo Achutti, constitui "uma narrativa visual que é enriquecedora com novos ângulos, com uma outra grafia" (Achutti, 1997: 77). Para entender essa narrativa imagética, devemos levar em conta a técnica fotográfica empregada para finalmente interpretar os resultados obtidos. Como não baseamos este escrito unicamente na sua 
metodologia textual de escrita e pesquisa, é importante ter clara a escolha de um método visual para a restituição/criação de uma realidade. É nessa concepção de um ponto de vista que entra a importância da fotografia HDR como processo subjetivo de sociologia visual.

\section{A fotografia HDR e seus reflexos}

Tratando-se do uso da imagem em sociologia - questão antiga e polêmica -, posicionamo-nos do lado de uma sociologia visual que, passado os anos 70 , não pretende ter na imagem apenas uma prova ou ilustração do terreno ${ }^{8}$. Nas fotografias que estão aqui apresentadas intuímos a visualização de uma organização social cotidiana. Levamos em conta o ponto de vista de Edgar Morin sobre a fotografia "como presença real da pessoa representada" (Morin, 1956: 28), sendo o real visto nas cabines telefônicas uma inferência sobre a realidade. As pessoas que utilizavam as cabines no momento da fotografia, assim como os tags vistos em seus vidros, são representativos genéricos da complexa ordem urbana parisiense. Fotografadas em ângulos pouco reveladores, as pessoas são amostras da diversidade étnica parisiense; e os tags, exemplos das assinaturas espalhadas pela cidade que se assemelham entre si na forma $\mathrm{e}$ conteúdo.

Na intenção de configurar a cabine telefônica como um objeto de análise, a fotografia é escolhida por ser uma maneira de a reportar ao texto. 0 nosso ponto de vista não repousa apenas na cabine telefônica em si, mas, sim, no jogo de espelhos percebido nas suas paredes envidraçadas. Podemos dizer que a criação fotográfica, realizada com a técnica do HDR (do inglês High Dynamic Range, em português, Grande Alcance Dinâmico), apresenta um universo onírico, um ponto de vista que trespassa a estrutura física da própria cabine, dando a ver uma cidade refletida.

Nessas fotografias de reflexos que se sobrepõem numa superfície envidraçada, o que nos chama a atenção é a comunicação urbana e toda uma sinalética que instrui e coage o habitante. Vemos que o corpo liso da cabine é carregado de signos, fortemente marcado por ranhuras feitas com diamante de cortar vidro e por sulcos, fruto de reação irreversível com o ácido sulfúrico. Essas marcas indeléveis vão acompanhar o vidro, que na cabine faz as vezes de parede, até ao fim de seus dias. Essas insígnias são elaboradas e não podem ser comparadas a rasgos que talham o vidro ao acaso. Elas são, mais precisamente, assinaturas cursivas: tags que indicam uma pessoa ou grupo de pessoas claramente definidos no quadro de uma tribo urbana, a que faz e/ou lê os graffitis.

Os tags feitos com ácido e diamante serão mais longamente observados. Antes é importante descrever um processo fotográfico que infere uma visão particular da cidade, ao mesmo tempo que cria um recorte da realidade. Diferente de uma fotografia tradicional, o HDR afeta a forma como a luz é preservada nos fenômenos ópticos de reflexão/refração, em especial sobre materiais transparentes como o vidro. Por permitir um controle detalhado das zonas de altas e baixas luzes, em programas como Photoshop e Photomatix Pro, o HDR possibilita a valorização dos reflexos, que são detalhes de cidade. Dizemos "detalhe" pois, como indica Omar Calabrese: "percebe-se a forma do detalhe, até que esta fique em relação perceptível com o seu inteiro" (Calabrese, 1987: 86). Esses detalhes da cidade são necessariamente reportáveis ao seu contexto urbano parisiense, diferente do que seriam fragmentos de uma cidade estilhaçada. 
31 Outra função do HDR é estilística e conceitual, cada foto apresentada aqui é composta por três fotografias quase idênticas, que diferem em relação com a medida de luz que entra na câmera: a primeira tem uma exposição-padrão, a segunda é subexposta e a terceira sobrexposta. Esse processo é chamado de bracketing. Posteriormente, as três fotos são agrupadas no programa Photomatix Pro num photomerge. Finalmente, as cores, sombras e brilhos do vidro são tratados pelo tone mapping, de forma a valorizar os reflexos da paisagem urbana.

32 As cabines telefônicas são o suporte físico para a ação de pessoas que fazem de sua assinatura uma obra. Quando nos dedicamos a observar esses tags com ácido fluorídrico, feitos também nos vidros dos metrôs e nas vitrines das grandes lojas, deparamo-nos com muito mais que um simples tag âmbar num vidro polido. As luzes e cores que atravessam o suporte transparente propuseram-nos a integração do tag num cenário específico, pois, quando não associado à cidade, ele corre o risco de se transformar numa simples assinatura.

33 Nesse artigo, a fotografia é o meio através do qual reproduzimos a cabine; o papel impresso é suporte para uma imagem que comunica com o leitor. Sendo a fotografia tradicional de baixo alcance dinâmico em relação à captação da luz, o HDR torna-se ferramenta para tentar reproduzir o que o olho capta. Dado que as fotos passam por um tratamento de imagem durante o seu processo de criação, elas ressaltam mais do que o olhar humano provavelmente veria nessas superfícies, tornando-se assim verdadeiras concepções a partir de uma base citadina.

Ao observá-las estaríamos frente a uma cidade que não existe? Poderíamos entrever um imaginário lúdico? É mais provável que nos deparemos com um suporte intersticial de forte efervescência subterrânea. Pois mesmo que observada ao nível da rua e à vista de todos, a cabine configura-se como um refúgio onde se orquestram elementos do "regime noturno" (Durand, 1992). Afinal, em frente dos olhos, as coisas escondem-se melhor. Na cabine, um sistema cíclico de renovação/ocupação se estabelece, originando uma "zona de sombra" (Maffesoli, 1991). Nesse espaço que escapa ao olhar totalitário do Estado, talvez pelo fato de ser transparente, temos não somente habitantes regulares como todo um ecossistema de usuários e de comunicações.

\section{Os usos da cabine}

Essas cabines que medem por volta de dois metros quadrados são usadas em geral por imigrantes que, munidos de cartões telefónicos pré-pagos, ligam para os seus respectivos países de origem. Sobre o telefone e no suporte de apoio metálico, repousam anúncios em línguas exóticas, visando poliglotas etnicamente selecionados. Por vezes a transparência do vidro é encoberta por pósteres e propagandas ilegalmente fixadas, assim como pela escrita fosca feita com o já mencionado ácido sulfúrico. É por essa ecologia típica de um microcosmos que interpretamos a cabine telefônica na cidade de Paris como um espaço intersticial. Um lugar que, por ser translúcido e claro, não suscita suspeita, ou melhor, que por ser transparente é invisível, fadando quem penetra seu interior ao desaparecimento.

36 As cabines telefônicas em Paris caíram gradualmente em desuso com a popularização da telefone móvel. O telefone celular foi integrado no cotidiano do citadino e causou uma mudança na forma como as coisas nos pertencem, ou melhor, como nós 
pertencemos às coisas que nos pertencem. Atualmente é comum vê-lo diretamente acoplado à orelha por meio de um fone Bluetooth, dando ares de cyborg ao mais comum dos seres humanos. Como se não bastasse, muitos de nós temos também a Internet vinte e quatro horas por dia na palma da mão, dentro de um Smartphone no estilo Blackberry ou iPhone. Frente a toda essa hiperconectividade, o telefone público, que nada mais faz do que telefonar, parece um tanto ou quanto ultrapassado.

Segundo o estudo de Fanny Carmagnat (2003), de 1998 a 2000 a receita das cabines telefônicas francesas sofreu um decréscimo de $20,6 \%$ e o volume das comunicações diminuiu em $28,1 \%$. Hoje em dia, é perceptível que essas cabines continuam funcionando sobretudo em cumprimento à lei nacional de $n^{\circ}$ 96-659 de 1996. Ela refere que a operadora histórica francesa, France Telecom, deve manter o chamado "serviço universal" que assegura o acesso público ao telefone. $O$ abandono em que elas se encontram é proporcional à queda na receita produzida. Segundo o jornal Le Monde: "os sindicatos acusam France Telecom de deixar ao abandono as 152000 cabines que ainda resistem à concorrência do telefone celular"'.

Devido a esse desuso progressivo, as cabines tornaram-se um espaço esquecido também por parte do Estado. A manutenção e a limpeza foram terceirizadas. Esses móveis desabitados ficaram entregues à selvagem natureza urbana. Neles, a intervenção com ácido feita pelos taggers é irreversível, sendo pouco provável que esses tags sejam removidos da pele citadina. As cabines tornam-se então um dos poucos suportes públicos da capital francesa, juntamente com o metrô, onde os tags não são completamente removidos.

Todavia, deve-se levar em conta que a partir da década de 90 a prefeitura de Paris passou a despender uma soma considerável de esforço e dinheiro para manter a cidade limpa ${ }^{10}$ dos graffitis e tags. É por isso que as cabines telefônicas e o metrô são o suporte de predileção para quem interfere com o ácido sulfúrico no suporte urbano. Eles tornam-se folhas incolores onde se depositam assinaturas indeléveis.

o habitante, por sua vez, detém um olhar habituado a esse mobiliário urbano. Podemos dizer, de forma bastante dicotômica e imediatista, que alguns deles não conseguem mais ver essas cabines, enquanto outros vêem nelas os reflexos de uma vida urbana intermediada por seus vidros: verdadeiros espelhos de tamanho humano. Outro tipo de habitante faz da cabine uma morada, uma cabana, um refúgio! São os chamados SDF (do Francês: Sem Domicilio Fixo), que com a chegada do inverno povoam o local. Essas pessoas adaptam-se ao exíguo espaço em posição fetal, na busca de um pouco de proteção para sobreviver ao frio da noite. Essa casa com seus múltiplos endereços, marcados pela assinatura do tagger, é impregnada com o próprio corpo do SDF. Ela pode ser interpretada pela analogia que Gaston Bachelard faz do caracol, pois segundo ele "deve-se viver para construir a casa e não construir a casa para vivê-la" (Bachelard, 1961: 106). É perceptível a relação de segurança, despertada por uma casa onírica, um ninho, quando taggers ou SDF fazem corpo com o objeto cabine.

41 Os taggers habitam a cabine telefônica por procuração. A posse é indicada, talhada no vidro. Sob a forma de rasgos quimicamente tecidos eles privatizam, com o "colorir", um pedaço transparente da cabine. Essa relação psicológica do tagger com a cabine pode ser aproximada pela reflexão de Bachelard para quem as palavras ... "são pequenas casas com porão e sótão" (Bachelard, 1961: 139). O senso comum estaria no andar térreo da casa, perto do contato com o "passante que não é um sonhador" (Bachelard, 1961: 139). Já descer ao porão ou subir ao sótão seriam de ordem fantasiosa, correspondendo a 
perder-se na deambulação por corredores de uma etimologia incerta. Os tags são antes de tudo palavras, nomes que escapam ao senso comum. Poucos procuram entender o sentido dessas palavras que fazem alusão ao seu autor e mantêm um significado codificado, um mistério conhecido pela tribo urbana dos grafiteiros.

o fato de dividirem um segredo é fator de coesão entre os membros e condiciona a relação deles com o resto da sociedade. Encontramos junto aos taggers resquícios do que Michel Maffesoli chama de centralidade subterrânea: "o segredo pode ser o meio de estabelecer contato com a alteridade no quadro de um grupo restrito; ao mesmo tempo que ele condiciona a atitude desse último em relação ao exterior" (Maffesoli, 2000: 169). Essa relação social com o exterior é oculta, misteriosa, underground. É da ordem de Hadès, Deus do subsolo que porta a kunée, capacete que o torna invisível. Subterrâneo, secreto e invisível são adjetivos válidos para entender a relação da assinatura tag com outros códigos da comunicação urbana, proporcional à que tem a cabine telefônica para com outros mobiliários urbanos.

Figura 4: NBK, Gare du Nord.

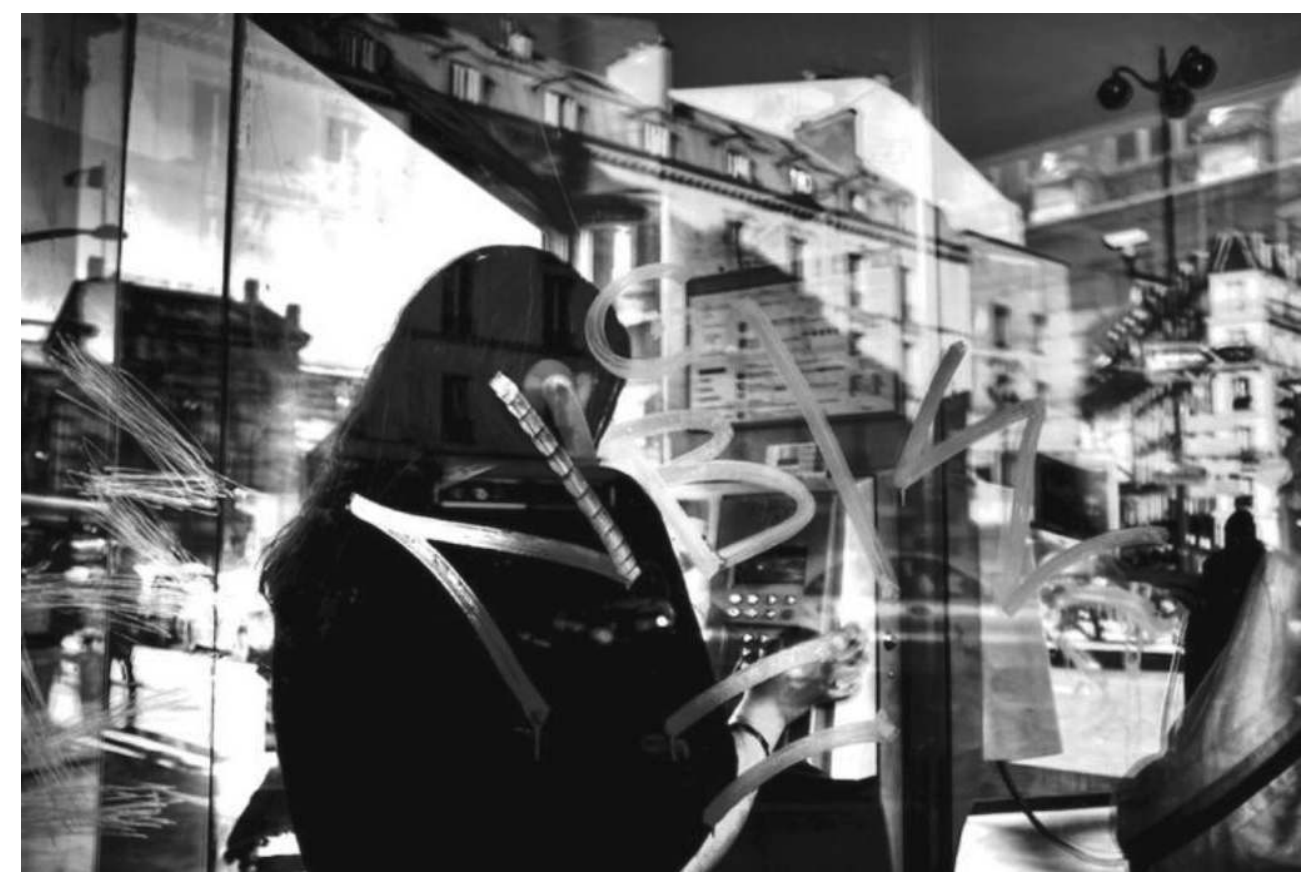

\section{Detalhes da cidade pós-moderna}

A cadência do obturador marca o passo do nosso percurso urbano. Nessa deriva, notamos que alguns elementos citadinos ganham outra amplitude quando colocados em evidência pelo quadro da câmera fotográfica. Resultantes de uma inter-subjetividade, as fotografias aqui apresentadas são narrativas autônomas. Não temos o objetivo de acrescentar uma legenda ou guiar a interpretação de quem as observa. Todavia, questões de ordem prática levam-nos a indicar, sob cada fotografia, onde a cabine se localiza em Paris e que tag nela está inscrito. A impressão em preto e branco é outro fator que dá nova roupagem às fotografias, originalmente coloridas, embora essa mudança de estilo não cause alteração de sentido. 
Vamos detalhar uma dessas fotografias no exercício reflexivo de descrever a Paris que nos salta aos olhos. Para isso é preciso aproximarmo-nos, como num zoom in, da fotografia intitulada NBK. Nessa fotografia o tag é central: nele está medido o foco, no caso, o nome do crew NBK. Informações paralelas que circundam o escrito sobressaem umas das outras, e anunciam o entorno localizando-o na cidade. Estamos frente a pormenores de Paris que remetem a um todo. Esses pormenores são aqui um punctum (Barthes, 1980), um pormenor que se destaca por dentre os ritmos do urbano e que atrai delicadamente o olhar de quem observa a fotografia.

$\mathrm{O}$ interesse que lhes dirigimos é aleatório mas constante. Podemos fixar o olhar num ou oscilar de um para outro. 0 todo é importante, afinal, se passarmos os olhos de forma circular pela fotografia, é difícil não notar as luzes dos semáforos que regem o ritmo do caos urbano. Placas coloridas indicam a ordem certa para carros e pedestres. Enquanto uma câmera de segurança filma a nossa ação, a bandeira francesa tremula triunfante. Dentro da cabine, uma mulher deixa-se guiar pelas indicações da France Telecom, com o objetivo de fazer uma chamada telefônica. Por entre as ranhuras feitas com diamante de cortar vidro vemos o reflexo de um ônibus a passar ao longe.

Essa descrição quase pictórica revisita alguns elementos de um impressionismo francês do século XIX, com novos signos e paisagens. O olhar é imerso em reflexos incertos e processos múltiplos de fotografia digital, que tentam tornar a realidade realista. Seria provavelmente mais atual interpretar esses signos urbanos como vozes e falar numa "cidade polifônica", como faz Massimo Canevacci. Em referência ao termo fotográfico estar "fora de campo", o autor afirma que: "o que está fora do campo visual - no sentido espaço-temporal e mental - torna a entrar nele graças à simultaneidade futurista. Os limites do quadro são anulados e modificados. A pintura é como a cidade: polifônica" (Canevacci, 1993). uma pintura, mas a polifonia urbana salta aos olhos. 0 nosso plano fotográfico que foca o tag NBK deixa voluntariamente entrever o território no qual ele está inserido e com o qual se comunica. Retirar essas três letras maiúsculas da cidade mutila a sua significação já frágil. Elas constituem uma voz sinestésica, de textura lisa e coloração âmbar, proferida por pessoas anônimas que povoam a iconografia parisiense.

Para leitores iniciados, o escrito NBK pode representar os integrantes que compõem esse crew, como os writers Soack e Toam. Ele passa a evocar um coletivo para as pessoas que se identificam com esse símbolo. Guardando as proporções inerentes a uma tribo pós-moderna, no nível do pacto e do "afetual" (Maffesoli, 2000); encontrar o nome de seu grupo no meio da paisagem urbana tem fator gregário para os writers. Sensação análoga é causada pela bandeira francesa ${ }^{11}$ junto da maioria da população. Essa outra relação é, porém, marcada pelas questões modernas do Estado Nação e seus valores contratuais.

Finalmente, vamos abrir espaço ao diálogo entre as referidas fotografias e o leitor. Sabemos que "a fotografia pode transformar não somente o olhar, mas o ambiente propriamente dito" (Kerlan, 2008: 18). A iconografia urbana que retratamos é um dos elementos que configura o habitat assim como o imaginamos. Compreender esse complexo sistema simbólico é uma tarefa subjetiva, pois um significante pode ter mais de um significado. A sociologia visual foi nossa aliada ao conformar a percepção que fazemos do ambiente estudado, permitindo a expressão de uma análise guiada por vias não verbais de comunicação. O exercício metodológico que realizamos com essa 
captação fotográfica aponta para a possibilidade de intuir um diálogo da ordem do sensível entre o sociólogo e o seu leitor, mostrando o mundo como ele nos importa. Mesmo que a argumentação textual seja imperativa no domínio das ciências sociais, a criação de um texto imagético pode guiar a pesquisa qualitativa e mesmo constituir uma escrita à parte. Com a expressão visual de um olhar educado sociologicamente, concluímos esse escrito dando vazão a uma grafia que compartilha o nosso ponto de vista sobre a socialidade parisiense em tardes ensolaradas do verão de 2009:

Figura 5: DORME, métro Barbés Rochechouart.

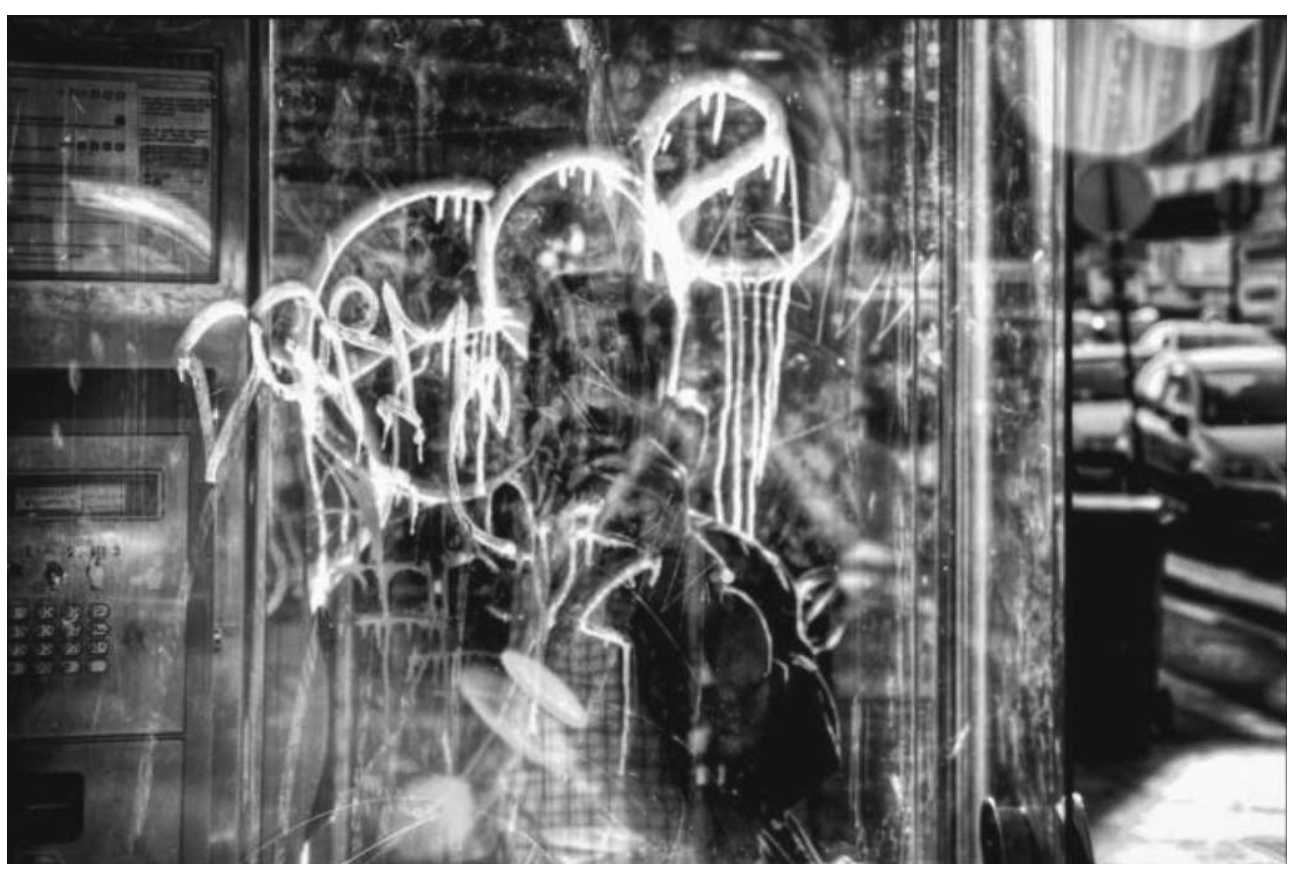

Figura 6: BZER, Gare Du Nord.

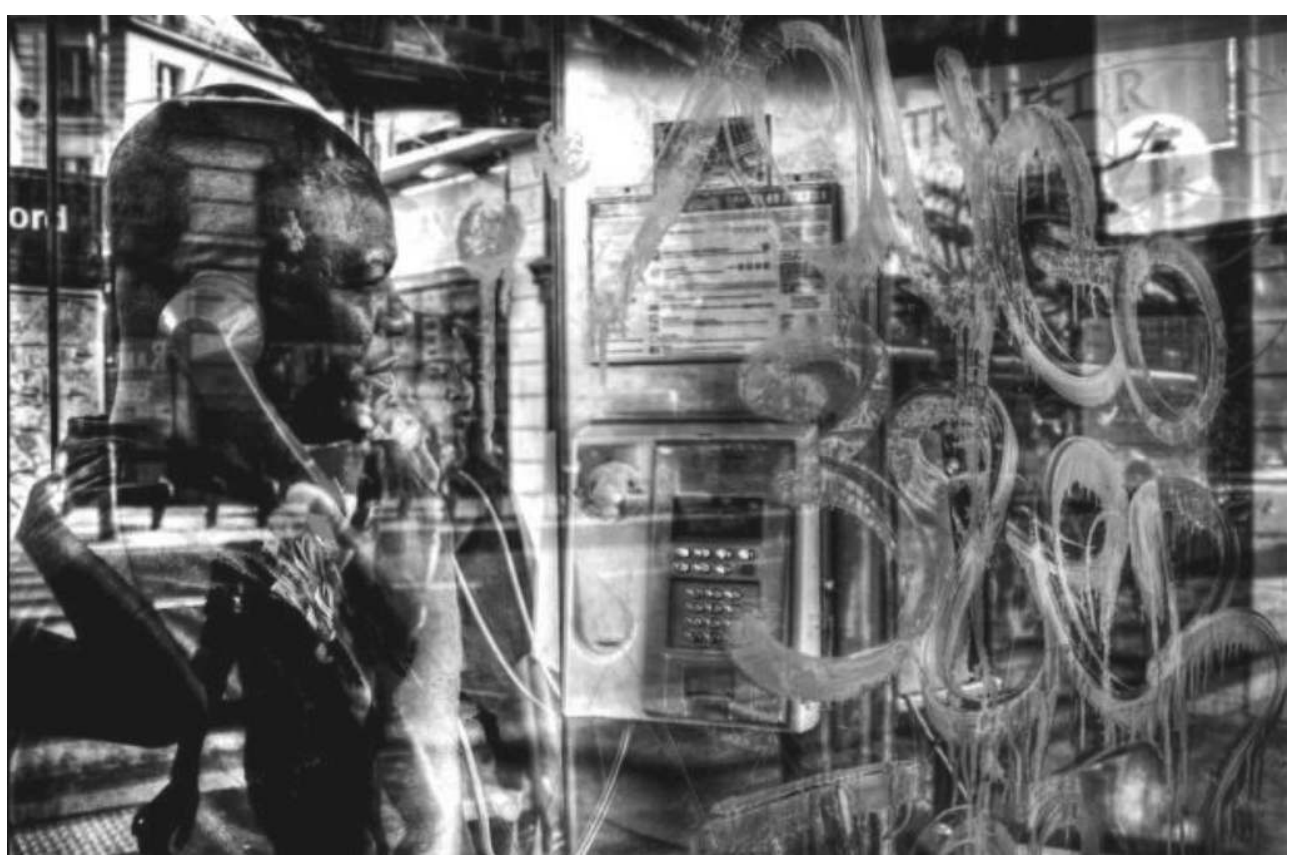


Figura 7: OPS DESOLE, métro Jacques Bonsergent.

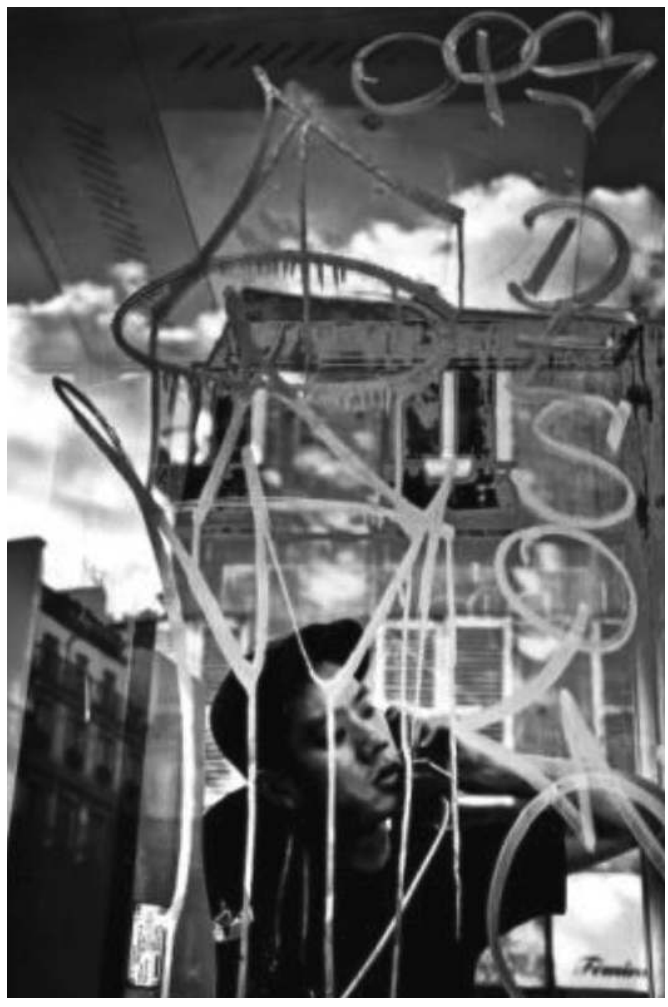

Figura 8: YOUGO BZER, Boulevard Sébastopol.

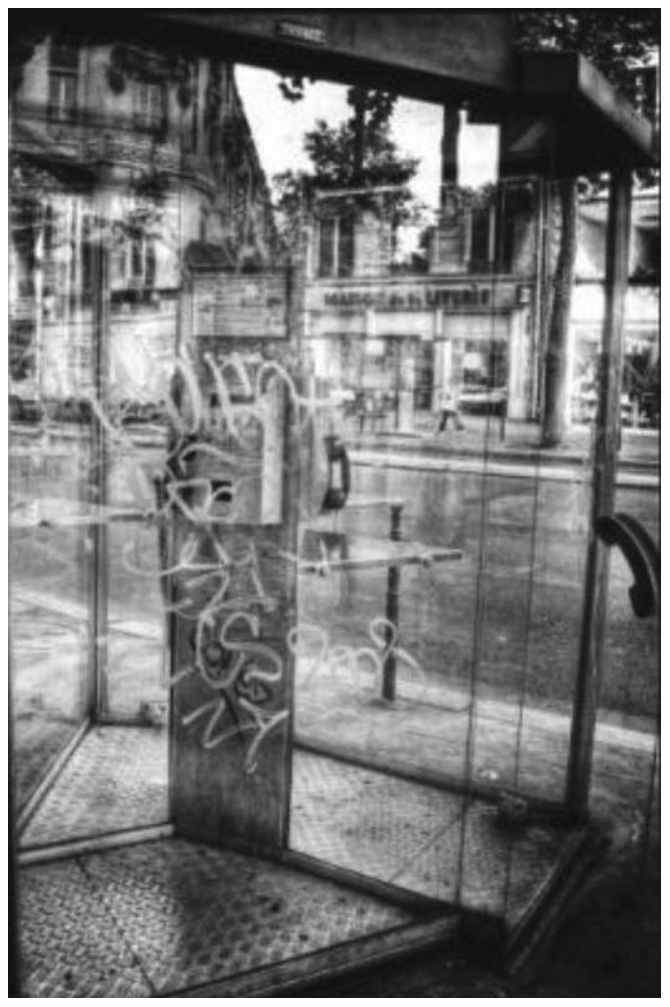


Figura 9: SOKLE, Boulevard Sébastopol.

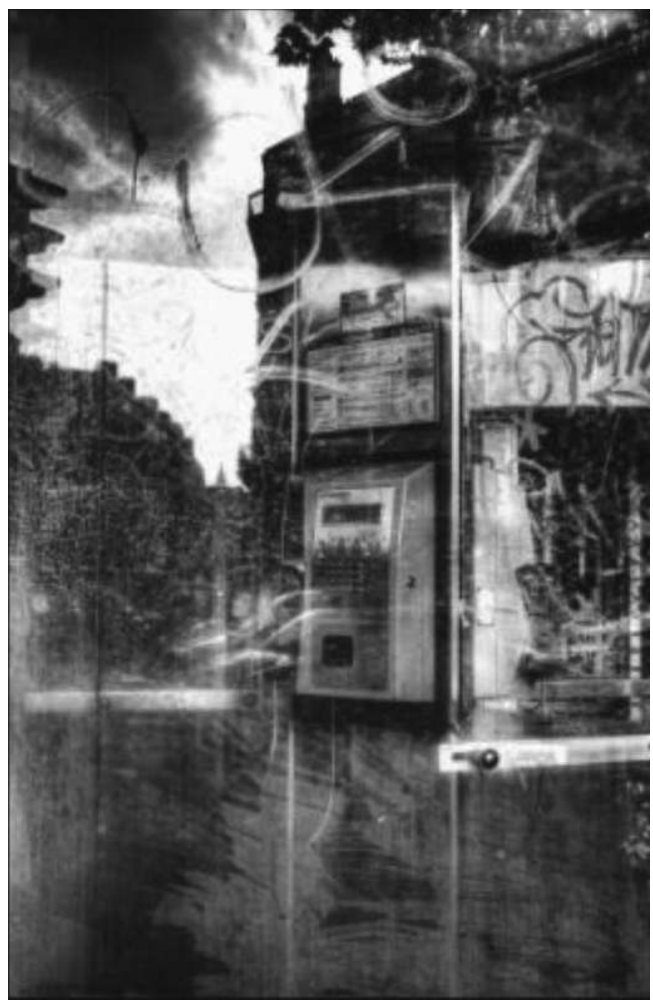

Figura 10: SKERT, Boulevard Sébastopol.

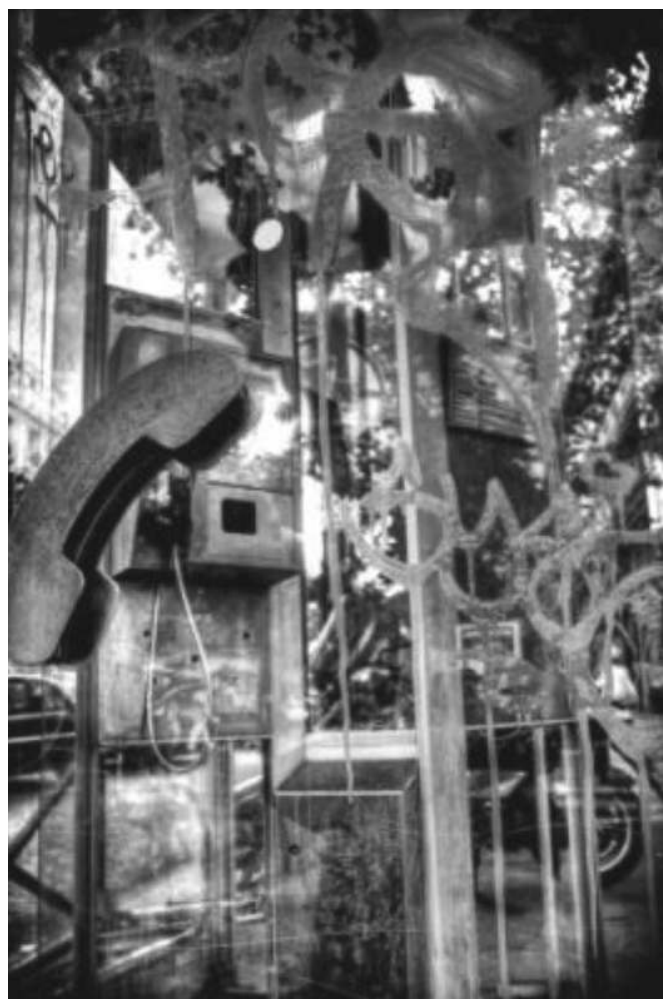


Figura 11: SAOR, Boulevard Sébastopol.

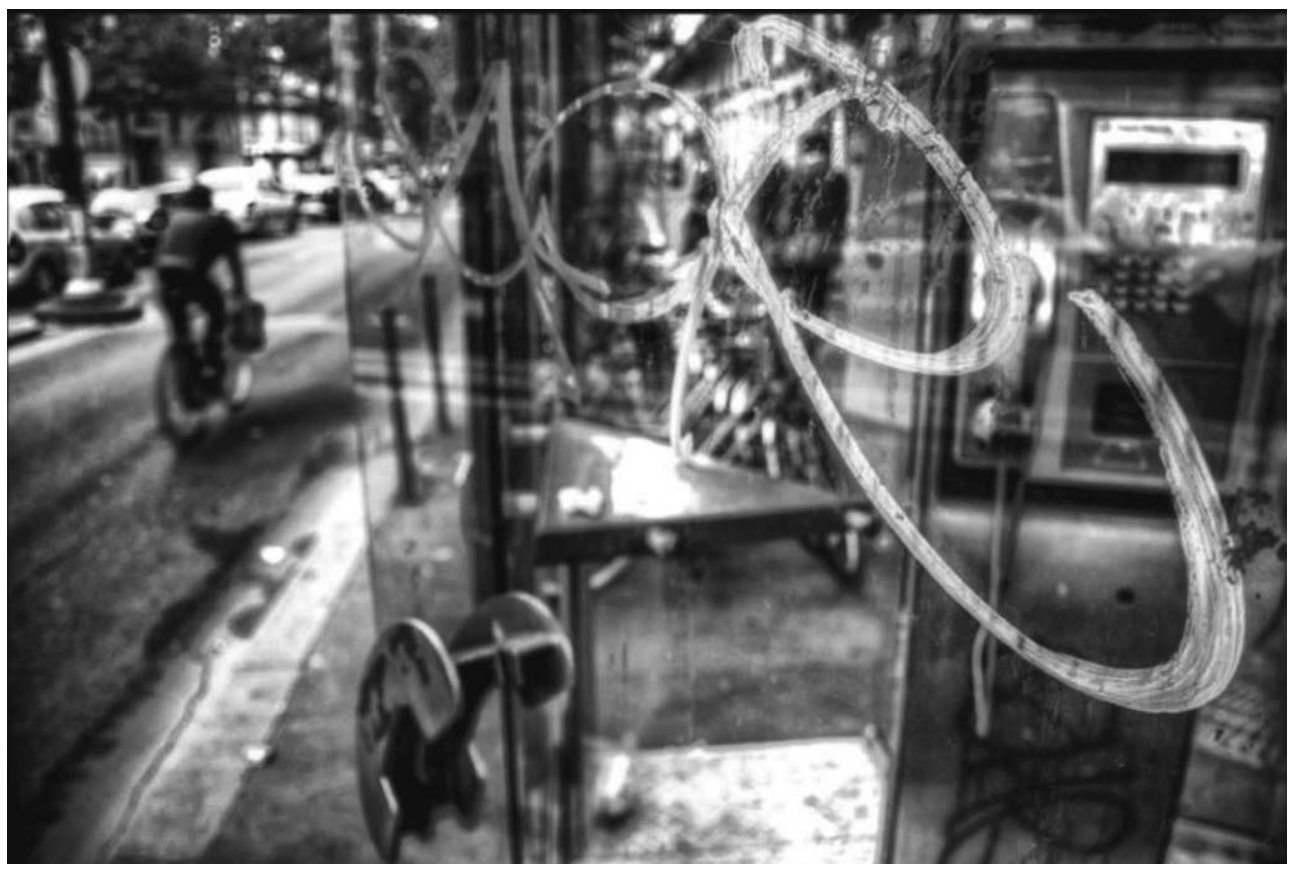

\section{BIBLIOGRAFIA}

ACHUTTI, L. (1997), Fotoetnografia. Um estudo de antropologia visual sobre o cotidiano, lixo e trabalho. Porto Alegre, Tomo Editorial Ltda.

AUGÉ, M. (2001), Un ethnologue dans le métro, Paris, Hachette.

AUGÉ, M. (1992), Non-lieux: Introduction à une anthropologie de la surmodernité, Paris, Editions du Seuil.

BACHELARD, G. (1961), La Poétique de l'Espace, Paris, PUF.

BARTHES, R. (1980), La Chambre Claire. Note Sur la Photographie, Paris, Cahiers du Cinema, Gallimard Seuil.

BATESON, G. e M. Mead (1942), The Balinese Character: A Photographic Analysis, New York, Academy of Sciences Special Publication.

BECKER, H. (1985), Outsiders. Étude de sociologie de la déviance, Paris, Métailié.

BENJAMIN, W. (1994), Charles Baudelaire. Um lírico no auge do capitalismo. Obras Escolhidas III, São Paulo, Brasiliense.

BENJAMIN, W. (1986), Paris, capitale du XIX ${ }^{\mathrm{e}}$ siècle: Le Livre des passages, Paris, Éditions du Cerf. BERQUE, A. (1990), Médiance. De milieux en paysages, Montpellier, GIP Reclus.

CALABRESE, O. (1987), A Idade Neobarroca, Lisboa, Edições 70. 
CAMPOS, R. (2009), “On urban graffiti. Bairro Alto as a liminal space”, in A. Brighenti (org.), The Wall and the City, Trento, Professionaldreamers, pp. 135-151.

CANEVACCI, M. (1993), A Cidade Polifônica, São Paulo, Livros Studio Nobel Ltda.

CARMAGNAT, F. (2003), Du service public au service universel: une approche historique du cas du service des cabines téléphoniques en France au XX in 2001 Bogues, Globalisme et Pluralisme, Québec, Les Presses de l'Univesité Laval.

CASTLEMAN, C. (1982), Getting Up, London, The MIT Press.

CRUZ, T. S. (2004), “Grafiteros: Arte Callejero en la Ciudad de México”, in Desacatos Revista de Antropología Social, n. ํ 14, pp. 197-226.

EVANS, P. (2002), Livable Cities? Urban Struggles for Livelihood and Sustainability, Californie, Etats-Unis, University of California Press Ltd.

FELONNEAU, M. e S. Busquets (2001). Tags et Grafs, les Jeunes à la Conquête de la Ville, Paris, L'Harmattan.

FERRELL, J. (1993), Crimes of Style: Urban Graffiti and the Politics of Criminality, New York and London,: Garland Publishing.

GOFFMAN, E. (1973), La Mise en Scène de la Vie Quotidienne, Paris, Les Ed. de Minuit.

GRAFMEYER, Y. e I. Joseph (1984), L'École de Chicago. Naissance de l'écologie urbaine, Paris, Aubier.

KERLAN, A. (2008), La photographie comme lien social, Paris, CNDP.

LARA, A. H. (1996), Grafite Arte Urbana em Movimento, São Paulo, dissertação de mestrado, USP.

LEMOINE, S. e J. Terral (2005), in situ: Un panorama de l'art urbain de 1975 à nos jours, Paris, Editions Alternatives.

MAFFESOLI, M. (2000), Le Temps des Tribus, Paris, La Table Ronde.

MAFFESOLI M. (1991), L'ombre de Dionysos, contribution à une sociologie de l'orgie, Paris, Livre de Poche.

MORIN, E. (1956). Le cinéma ou l'homme imaginaire. Paris: Les éditions de minuit.

SPINELLI, L. (2007), Techniques visuelles dans une enquête qualitative de terrain, Paris Société $n .^{\circ}$ 96, pp. 77-89.

SPINELLI, L. (2007), Pichação e comunicação: um código sem regra, Revista Logos UERJ n.o 26, pp. 111-121.

TIMMER, V. e N. K. Seymoar (2006), La ville habitable: Document de travail du Groupe de travail de Vancouver, Vancouver, Université de la Colombie-Britannique Vancouver.

\section{NOTAS}

1. Uma cidade habitável segundo Peter Evans, para quem "A habitabilidade tem dois aspectos: os meios de subsistência e a durabilidade”, Evans, P. Livable Cities? Urban Struggles for Livelihood and Sustainability. Californie, États-Unis: University of California Press Ltd. 2002.

2. Ver: Spinelli, L., Techniques visuelles dans une enquête qualitative de terrain. Société $2007 / 2 \mathrm{n} .^{\circ} 96$, pp. 77-89 e Spinelli, L., Pichação e comunicação: um código sem regra. Revista Logos UERJ 2007/1 n.o 26, pp. 111-121. 
3. O interaccionismo simbólico é herdeiro da Escola de Chicago desenvolvido a partir dos anos 50 nos Estados Unidos. Apontando para a construção do indivíduo em relação com o próximo e seu meio social, a consolidação da perspectiva interaccionista dá-se nos anos 70 com autores como: Howard Becker, Outsiders. Étude de sociologie de la déviance. 1985 Paris: Métailié e Erving Goffman, La Mise en Scène de la Vie Quotidienne. Paris: Les Éd. de Minuit. 1973.

4. Uma assinatura que segundo Felonneau e Busquets "funciona como um logo, uma etiqueta publicitária" (Felonneau e Busquets, 2001: 77).

5. Estes anglicanismos são definidos por Craig Castleman no livro Getting Up. London: The MIT Press. 1982.

6. A fama em questão é inicialmente conquistada dentro da tribo urbana dos writers e posteriormente pode derivar de obras de arte urbana e da exposição na mídia alternativa.

7. Um crew é um grupo de writers que pintam um nome em comum, esses grupos são, segundo Craig Castleman, formados por: "companheirismo e ocasionais aventuras de graffiti. Os membros do grupo também consideram a escrita dos próprios nomes como mais importante que a afirmação do nome do grupo" (Castleman, 1982: 107).

8. Como era o caso do uso da fotografia nas descrições feitas por Gregory Bateson e Margaret Mead, na obra The Balinese Character: A Photographic Analysis, New York, Academy of Sciences Special Publication, 1942.

9. Artigo publicado no Le Monde do dia 24 de maio de 2009 por Cécile Ducourtieux.

10. Sobre a limpeza e criminalização dos graffitis na França ver a obra de Felonneau, M. e Busquets, S., Tags et Grafs, les Jeunes à la Conquête de la Ville. Paris: L'Harmattan, 2001.

11. Que vemos na foto, no alto do edifício à esquerda.

\section{RESUMOS}

Com o intuito de ler a cidade, vamos observar fractais coloridos da vida cotidiana refletida nas cabines telefônicas de Paris. A partir da realização de fotografias HDR que focalizam os graffitis e tags feitos com ácido fluorídrico nessas cabines, vamos perceber outra cidade através de seus vidros. É pela educação do olhar junto de alguns graffiti writers que inferimos uma visão fenomenológica sobre a socialidade pós-moderna, para entender a relação fusional que se dá nesse mobiliário urbano entre habitante e habitat.

Day life reflected on the telephone booths of Paris. Thanks to HDR photographs, we highlight the hydrofluoric acid tags and graffitis made in these booths, seeing another city through it. From a point of view educated with some graffiti writers, we take a phenomenological perspective to understand the postmodern sociality and the relationship between the citizen and his habitat.

\section{ÍNDICE}

Keywords: urban communication, telephone booths, graffiti/tag, HDR photography

Palavras-chave: comunicação urbana, cabine telefônica, graffiti/tag, fotografia HDR 
AUTOR

LUCIANO SPINELLI

Centre D'Études sur L'Actuel et le Quotidien, Université René Descartes - Sorbonne Paris V lucianospinelli@gmail.com 